\section{THE IRISH MEDICAL DEGREE PRIOR TO 1858.}

To the Editors of THE LANCET.

SIRS, - In a book lately published by Mr. R. Brudenell Carter entitled "Doctors and Their Work," the following statement occurs (p. 8): "While such was the state of things in Fngland (i.e., prior to the Medical Act of 1858) it had been from time immemorial the custom of Scottish and Irish universities to confer degrees in medicine after examinations which were mainly medical in their scope, and which could not be held to establish more than a modest amount of acquirement in scholarship or general knowledge. In these divisions of the Kingdom, therefore, the degree and title of 'Dr,,' instead of being confined to the highest grade of the profession, belonged of right to the great body of general practitioners and represented something essentially different from that which they represented in England."

As far as Ireland is concerned nothing could be more remote from the truth. The University of Trinity College, which up to 1852 was the only university in Ireland, has from time immemorial made a degree in arts an indispensable condition of degrees in medicine, as well as in all other faculties, except music. Among the "Regulæ Universitatis Dubliniensis" is this: "Ad Baccalaureatum in Medicina nemo admittatur qui prius Baccalaureatum in Artibus non susceperit." Not only so, but of all British universities Trinity College is (with the comparatively unimportant exception of Oxford) the only one all of whose graduates in medicine are also of necessity graduates in arts. It is true that at the time of which Mr. Carter speaks there were many general practitioners and apothecaries in Dublin styling themselves "Dr.," but they invariably had Scottish qualifications. Mr. Carter has promised to correct the error should his book reach a second edition. I am, S.rs, yours faithfully, T. K. ABBOTT,

Senior Fellow and Senior Proctor, Trinity College, Dublin.

\section{OPIUM AND PNEUMONIA.}

\section{To the Editors of THE LANCET.}

SIRS, - I was much interested in your leader in a late number on the subject of "Opium and Pneumonia" because I have been convinced for the past 15 years that that drug has a deal to answer for in the mortality from the disease. Let us consider what is the condition at the moment of crisis of that grave disorder. The lung is occluded with a thick tenacious slime almost impossible to throw off. The right heart is battling to get the blood through this occluded lung. And what is done by giving opium or any of its derivatives? The tenacity and thickness of the slime is increased and at the same time the heart's power is enfeebled and bewildered, also that of the respiratory centre. Could any therapeutic power be less well directed? We enfeeble and shackle the cardiac and respiratory powers at the very time their utmost strength is required and at the same time add to the obstructive power, the tenacity and dryness of the slime. Surely this is clear, but what is the excuse for such a mode of treatment? Oh, it dulls and stills pain and restlessness and the patient "feels better." Better? Yes. Euthanasia! The necessary pain and restlessness must not be dulled; they are requisite for recovery. Exoessive pain may be relieved by other means-a few leeches, an ice-bag, \&c., or even a minute hypodermic dose of morphia not sufficient to have a constitutional effect. Aconite, too, is a most dangerous drug in pneumonia, given to "lower the temperature." But, alas, it paralyses the cardiac centre. Such drugs as digitalis and strychnine must also be given with great discretion, for though they may increase the cardiac power it must be remembered that they also increase the muscular tone of the arteries and therefore resistance to that power.

Now it is universally admitted that pneumonia is due to a microbe and its toxins. It appears to me that treatment should be directed to the destruction of that microbe and its effects and that symptomatic treatment should be entirely secondary. With that view I have now for many years prescribed salicylate of soda with liquor ammoniæ acetatis and in suitable cases (threatened heart failure) spiritus ammonia aromaticus. The salicylate not only helps to arrest the rapid multiplication of microbes but it rapidly throws off the toxic products through the kidneys. The acetate of ammonia not only counteracts any cardiac depression (though I have never noticed any as especially due to the salicylate) but also liquefies and loosens the thick "slime" in the lung and makes it the more easy to expectorate it. If we cannot be sure we are giving the right drug let us stand aside. Nature alone will do better than we. Let us be sure we do not add the last straw to the burden in the terrible crisis.

Influenced by these views I have in later years only used the drugs I have mentioned in this dire disorder and the result has been that I have never lost a case. I have had most serious cases, one in delirium tremens where another medical authority thought there was no hope, but the patient rapidly got well. Within the last few months I have had two cases of pleuro-pneumonia in aged people the results of which are striking. The one, aged 69 years, a very healthy life previously, declined to take the salicylate, as he said it made him feel sick. He recovered from the immediate attack but developed an empyema which, after repeated aspirations (the pneumococcus abundant in every specimen of the pus), killed him by developing complications elsewhere (operation was declined). The other, aged 76 years, an equally severe attack, took the salicylates readily, had a copious serous effusion in the pleura, but has recovered completely.-I am, Sirs, yours faithfully,

Lancaster, March 6th, 1904. O. A. RAYNE, M D. Lond., \&c.

\section{THE SETON IN MÉNIËRE'S DISEASE.}

\section{To the Editors of THE LANCET.}

SiRs,-Referring to Dr. T. Wilson Parry's very interesting communication, may I be permitted to point out that I described a case of Ménière's disease successfully treated by the seton in the British Medical Journal of March 29th 1902 , p. 806? It was suggested to me by Mr. Walter Whitehead's remarkable success in the treatment of migraine. I am, Sirs, yours faithfully,

Southport, March 8th, 1904. COLIN OAM PBELL.

\section{THE ADULTERATION OF COD-LIVER OIL.}

To the Editors of THE LANCET.

SIRS, - I am perfectly in agreement with Mr. E. J. Parry in his contention that the value of cod-liver oil is due to the facility with which it is digested and absorbed and not to any active principle. In this sense his use of the word "traditional" is justified and therefore possibly other fats have not had their fair share of consideration. Virol, to which he refers, the fatty portion of which is chiefly supplied by bone-marrow, is a substance which we have largely used at the Children's Hospital here with excellent results, young children taking it with facility and advantage. Possibly it would be well, remembering how scarce and expensive cod-liver oil has become, if we were to investigate the whole subject of the value of the various available animal fats de novo and determine their relative advantages on their merits alone, eliminating any element of tradition.

I am, Sirs, yours faithfully,

Hove, Sussex, March 8th, 1904

L. A. PARRY, M.D. Lond., F.R.C.S. Ing.

\section{NOTES FROM INDIA.}

(FROM OUR SPECIAL CORRESPONDENT.)

\section{Vacoination amongst Ancient Hindus. - Increase of Plague.}

A POINT of immense historical interest has lately been referred to by a writer in the Madras Mail. It practically consists in the discovery that vaccination as we know it, and not merely inoculation for small-pox, was practised in ancient Hindu days. In the "Sactaya Grantham," an ancient treatise attributed to Dhanwantri, the writer after describing nine species of small-pox lays down rules for the practice of inoculation (? vaccination). The translation of the passage is as follows: "Take the fluid of the pock on the udder of a cow or on the arm between the shoulder and elbow of a human subject on the point of a lancet and lance with it the arms between the shoulders and elbow until the blood aprears; then mixing the fluid with the 